\title{
Aspects of designing construction of balcony parapets with photoelectric cells
}

\author{
Ilya Dunichkin ${ }^{1, *}$ \\ ${ }^{1}$ Moscow State University of Civil Engineering, 129337 Yaroslavskoye sh. 26, Moscow, Russia
}

\begin{abstract}
The aim of the work is to develop a modular system design of the balcony parapets of photoelectric panels "photoelectric barrier" (the "PB"). As a result of research conducted it has been identified the dimensions of the module "photoelectric barrier" ("PB"), height $1200 \mathrm{~mm}$ and width $1000 \mathrm{~mm}$. The Parapet design parameters have been determined and technological problems have been posed. The design of the module "PB" has been explored, elements that make up the module design have been developed. Subject to the requirements, objectives and constraints there were designed sketches and design drawings that were evaluated by physical influences. While determining the design parameters it was used in the calculation of the energy potential and the designation of the optimal size of the modules "photoelectric barrier". It is possible to identify the optimum size of the module design and the energy potential of the project. The article gives full view into the scientific work of its prospects and applications of developing design "PB" module, as well as forms the foundation for the development and research of the issues of management and organization in the implementation of the design in the real construction
\end{abstract}

\section{Introduction}

The urgency of this development and its advantages include the innovative use of renewable energy technologies in the balcony railings, renewable energy technology deployment opportunities in any object of the construction industry in new construction and renovation, the formation of a new quality of exterior and energy supply of buildings and structures, ease of implementation in industrial and construction production run spread with large-scale production through its retail sales network and use as a household appliance.

\section{The calculation of the energy potential and defining the optimal size of the "photoelectric barrier" modules}

To determine the parameters of the module "PB" is necessary to submit the basic model. Photoelectric panel module "PB" is made up of solar cells, the type of which will influence on the energy potential of the module. Consequently, the parameters of the module size and its energy potential are interdependent.

\footnotetext{
* Corresponding author: ecse@,bk.ru
} 
According to the materials presented in the research works of D.S. Strebkov and his team to efficiently convert solar energy into electricity photo converter plane must be oriented perpendicular to the direction of radiation. In stationary mode photo converter must be oriented it at an angle equal to the latitude of the area, taking into account seasonal correction for tilt of Earth's axis. [1]

The scope of application of the balcony fences "PB" are balconies of residential and public buildings. The development can be applied both in new construction, the mass and the individual, and in the reconstruction. To use the "PB" on the territory of the existing centralized power network its required an economic analysis, which will be executed in subsequent phases of research. Therefore, there will be inspected the territory, where the application module "PB" will be competitive, [2]. Large areas with favorable conditions take place in areas with low-density development. In view of this it is advisable to orient the use of the module on new construction.

The question of application of photoelectric panels in the new energy efficient construction was considered by the author in the pilot project "eco-settlement" GENOME "and presented on the World Renewable Energy Forum (WREF 2012) and Including World Renewable Energy Congress XII and Colorado Renewable Energy Society (CRES), [3]. The result of the study is the conclusion that the most effective use of the modules "PB" in the new building must be designed with an extended front of the building or special plastic south facade.

Studying urban development for the application module "PB", exactly, the orientation of the buildings on the sides of light, it can be concluded that a significant part of the buildings in Russia are located without orientation relative to the cardinal, considering many other factors shaping development. The norms in residential buildings is permitted according on the number of rooms, insolation values equal to one and a half to two hours [4]. Therefore, relying on sun exposure balcony railings throughout the day in dense urban areas is not advisable.

Based on this materials, you can define the measure for the development of the module above "PB". Photoelectric panels in the module "PB" should be able to change its position according

to: 1. The horizontal axis of rotation, as depending on the geographical latitude of its installation, the panel must be adapted to the angle to the horizontal. 2. The vertical axis of rotation, for use in buildings that are not oriented in a southerly direction.

To determine the optimal size of the module, and as a consequence its efficiency it is necessary to develop a conceptual model of the fence construction.

GOST 25772-83 "Fences of stairways, balconies and roofs of steel" sets the normative parameters of protections. Fences must withstand the loads specified in SNiP 2.01.07-85* "Loads and effects", including wind loads.

In addition, it should be noted that the application of these modules on buildings and structures of high level of responsibility, must take into account their impact on the distribution of the average and peak values of wind loads on the facade. Current regulations for these building structures [5], regulate carrying out of experimental studies in specialized wind tunnels. The methodology of these tests is described in detail in [6, 7]. Determining the above criteria for the development of the module "PB", you can make of the fence design concept model. Since solar photoelectric should be located at a certain angle to the supporting framework fence, depending on the geographical location of the place of its application, the panels of solar cells should be articulated at the upper point of attachment "A" and the value of " $b$ " should be changed to adjust the tilt angle panel «a». To orient the panel in a southerly direction it is necessary to provide rotation about point " $\mathrm{A}$ ", Fig.1. 
While developing the module "PB" solved the problem of placing the maximum number of solar cells in the photoelectric panels for the most efficient work. The width of photoelectric panels will be equal to the module width, $1000 \mathrm{~mm}$, and the panel height will be equal to $1090 \mathrm{~mm}$. Due to the placement of the module "PB" on the balcony of the building it must take into account the ratio of emerging wind load and mechanical strength of the panel and enclosure design. Therefore, taking into account the maximum size of the photoelectric panels, to reduce the impact of dynamic loads of the environment it is proposed to reduce the linear dimensions of the panels photoelectric module without reducing the total area of "PB". In this regard, in the module "PB" must be reduced two times a linear panel dimensions. On the basis of the above-defined parameters it will created a sketch of the module base model "PB", Fig. 2. Fig. 3 shows the geometry of the light beam falling on the photoelectric panel module "PB".
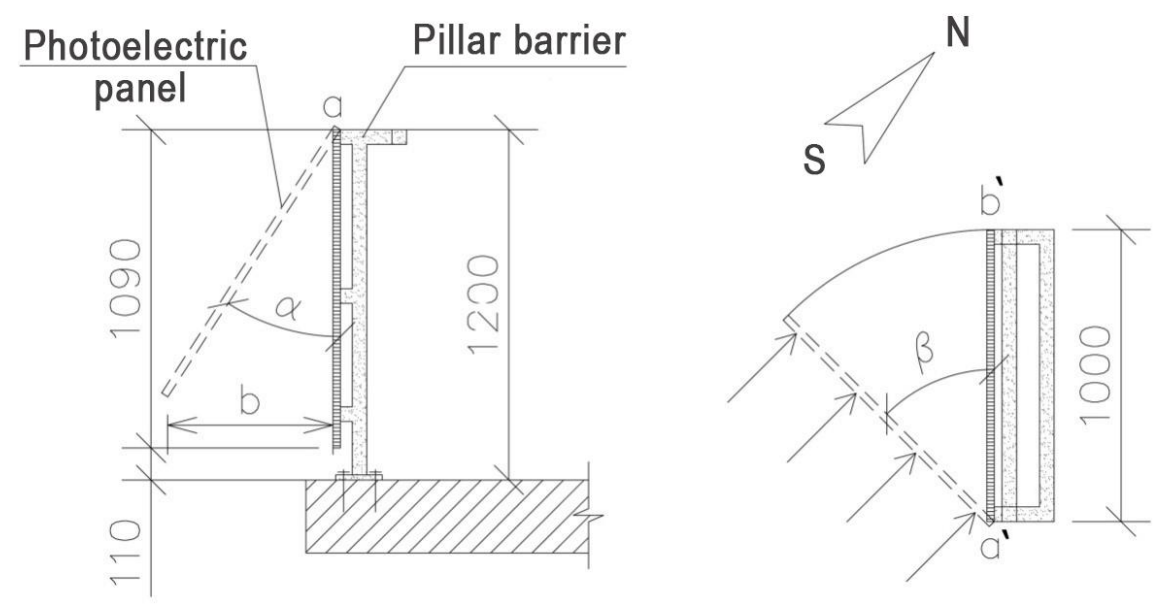

Fig. 1. Driving orientation of photoelectric solar panels

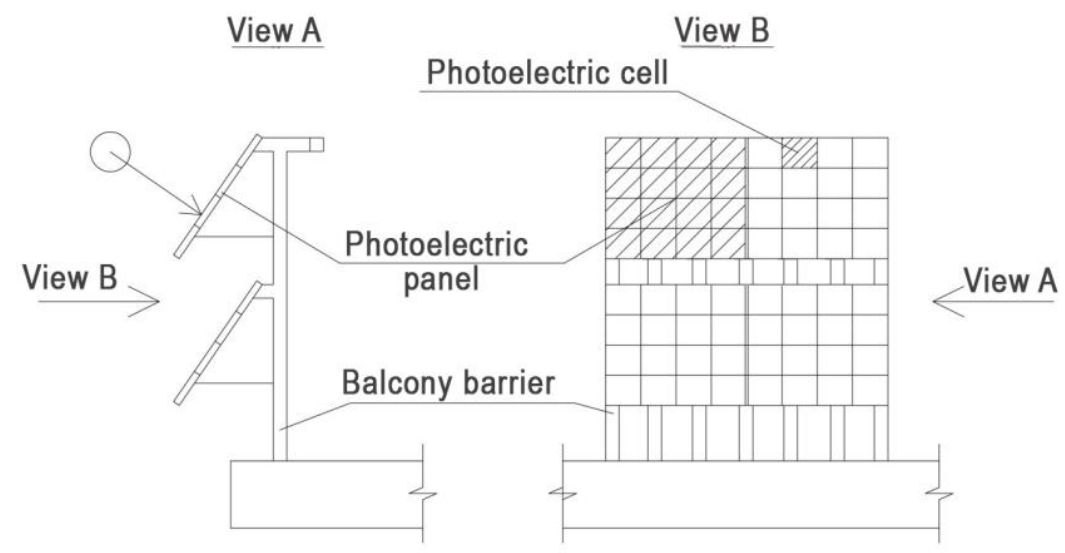

Fig. 2. Basic module model "PB"

We define the effective area of a panel of solar cells:

$$
\mathrm{S} 2=\mathrm{S}-\mathrm{S} 1=\mathrm{h} *(\mathrm{~L}-\mathrm{L} 1)
$$

where: S-area panels, S1-shaded area, S2- effective area, h-panel width. 
Substituting (1) into (2) we get:

$$
\mathrm{S} 2=\mathrm{h} *(\mathrm{~L}-(\mathrm{L} * \sin \alpha * \tan \beta-\mathrm{b}) /(\cos \alpha+\sin \alpha * \sin \beta)),
$$

With increasing angle shading area increases, which will affect the efficiency of the module "PB", and will reduce the amount of generated electric power module. Because of the problem, one of the questions that should be solved in the development of design drawings - is to minimize the area of the shading of photoelectric panels. Therefore, in determining the capacity of the power module "PB" is should be neglected area shading, considering that the entire area of the photoelectric panels module "PB" insolates throughout the daylight hours.

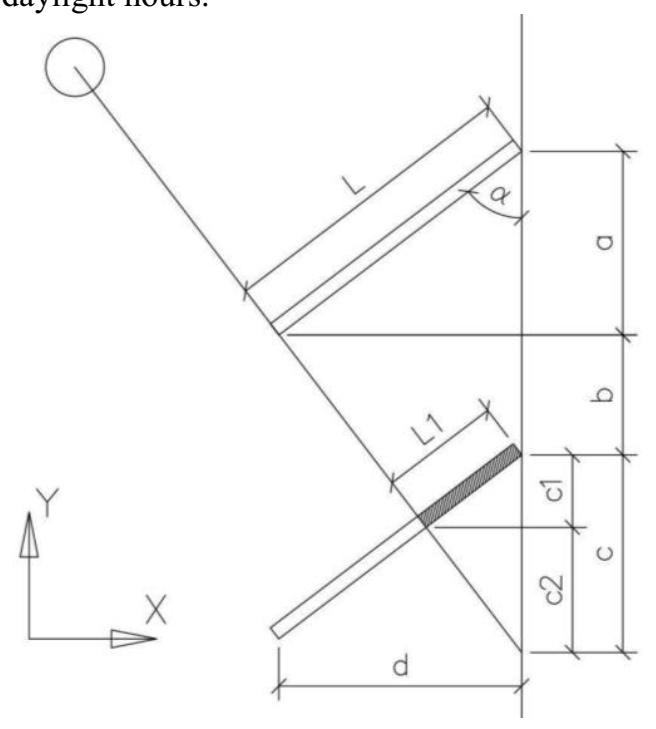

Fig. 3. Scheme of photoelectric panels in the module "PB" in the horizontal plane.

With increasing angle shading area increases, which will affect the efficiency of the module "PB", and will reduce the amount of generated electric power module. Because of the problem, one of the questions that should be solved in the development of design drawings - is to minimize the area of the shading of photoelectric panels. Therefore, in determining the capacity of the power module "PB" is should be neglected area shading, considering that the entire area of the photoelectric panels module "PB" insolates throughout daylight hours. Exploring the energy potential of the module "PB" on the example of the city of Krasnodar.

The annual amount of total solar radiation on a stationary platform oriented to the sun at an angle of 35 is $1433 \mathrm{kWh} / \mathrm{m} 2$. [2] Consequently, the energy potential of the "PB" module will be equal to:

$$
\mathrm{P}=(\text { EFFICIENCY) } \times \mathrm{R} \times \mathrm{S},
$$

Where P-Power, R-total solar radiation on $1 \mathrm{~m}^{2}$, S-area module panel [8] Substituting the data we obtain: $P=286,6 \mathrm{~kW}$ per year Check the results. We choose the basic element for the solar panel with the approximate performance efficiencies and consider the duration of sunshine in the territory of Krasnodar. Knowing these parameters, we can calculate the energy potential of the module "PB". The energy potential of "PB" module will be equal to:

$$
\mathrm{P}=\mathrm{Pi} * \mathrm{n} * \mathrm{t} * \mathrm{k},
$$


Where $\mathrm{p}$ - power, n- number of elements in the module, t-sunshine duration, $\mathrm{k}$ correction factor for the visible spectral range, perceived photodetector equal to $\sim 0.7$. [9] Substituting the data we obtain: $\mathrm{P}=274,12 \mathrm{kWh}$ per year. The difference in results is $4 \%$, which is slightly due to the averaging of original data. One module "PB" can produce about $280 \mathrm{kWh}$ per year if it is used in Krasnodar. Therefore, depending on where the application module in the territory of the Russian Federation of its energy potential will be taking into account the constraints of territories, suitable for its application, the duration of sunshine from $200 \mathrm{kWh}$ per year to $290 \mathrm{kWh}$ per year.

\section{Development of design and construction drawings modules "photoelectric barrier"}

As a result it was identified the criteria that influence the size of the module parameters and its energy potential, as well there were determined the size of the module "photoelectric barrier", height $1200 \mathrm{~mm}$ and width $1000 \mathrm{~mm}$, and the parameters of its parts. The module consists of a frame fence and 4 attached on it photoelectric panels 2 having an axis of rotation (2 degrees of freedom). As a basic element for the construction of photoelectric panel sized $500 \mathrm{~h} 545 \mathrm{~mm}$ took $125 \mathrm{~h} 125 \mathrm{~mm}$ photoelectric cells [10]. These options take the starting point for the development of the fence construction. Due to the problem of shading of adjacent photoelectric panels, it is necessary to develop a design that can minimize area of the shading of photoelectric panels

In this case, the two vectors of fences constructive scheme can be considered:

1. Monolithic module design, without fractional structure that leads to its rise in price. In this case, it needs economic analysis of the appropriateness of the design type with the possible reduction of the energy efficiency of the module "PB"

2. Developing fractional structure design, with technological improvements module design "PB" to solve the problem of shading of solar panels, Fig. 2.

To develop the most efficient design in terms of construction work and design aspects of economic criteria should be introduced, which will adhere to the further study, and that will build in the development of the module design "PB":

1. Using of rolled profiles and cost-effective materials in the development of elements of "PB";

2. Using a unified standard construction elements;

3. Developing the module construction "PB" and its elements based on existing regulations;

4. Considering the operating conditions of the design performance of the materials in the design and calculation;

5. Design a structure with minimizing labor costs in its manufacture;

6. Select the optimum technical and economical production of circuit elements

It is necessary to consider the requirements of regulatory documents. Fencing design should withstand the regulatory burden [5].

The characteristic values of horizontal loads on the rails of railing balconies and loggias should be equal to:

a) for residential buildings, kindergartens, rest homes, health centers, hospitals and other medical institutions $-0.3 \mathrm{kN} / \mathrm{m}(30 \mathrm{~kg} / \mathrm{m})$;

b) for the stands and gyms $-1.5 \mathrm{kN} / \mathrm{m}(150 \mathrm{kgf} / \mathrm{m})$;

c) for other buildings and premises in the absence of specific requirements $-0.8 \mathrm{kN} / \mathrm{m}$ $(80 \mathrm{~kg} / \mathrm{m})$.

According to SNiP 2.08.01-89* fencing loggias and balconies in buildings with three floors and more should be made of non-combustible materials. 
Based on the regulations and the economic aspect, it should be used steel profiles for fence structure.

SNiP II-23-81 * provides guidance for the design of metal constructions, which coincides largely with the proposed criteria for the development of the above structures.

To develop design drawings it should be considered components of the module "PB". The construction of the fence can be divided into three main parts:

1. Ball fence frame (rack and rail)

2. Filling the frame fence

3. Photoelectric panels with fastening

The front is the main carrier of the module "PB", which are attached to the brackets with photoelectric panels, mounted handrail and fence filling. Racks must ensure the safe operation of the module and accept all major loads applied to the module. Racks are mounted vertically and are fastened to the base of the balcony, set the parameters of the height of the fence, which normalized.

Handrail parapet is the most important element to ensure human security. The handrail is attached horizontally to the fence uprights with handrail bracket. Brackets can be in one piece and hinged. Articulated provide the ability to install the rail fence at an angle. By the racks and the rail bracket can be attached by welding or by using prefabricated compound.

Filling the frame fence has a safety feature, as well as decorative. To ensure the reliability and solidity of construction it is proposed to use the module "PB" through filling [11]. This frees up rack enclosure for mounting on the plane her arms design with photoelectric panels.

Photoelectric panel mounting bracket has carrier function, it is fixed to the solar panel, as well it has adaptive function, that gives opportunity to change the angle of the solar panel, depending on the operating conditions. Solar panel mounting brackets can be singleand dual-axis. Scheme of the device one axle brackets are more economical and is showed on Figure 4.

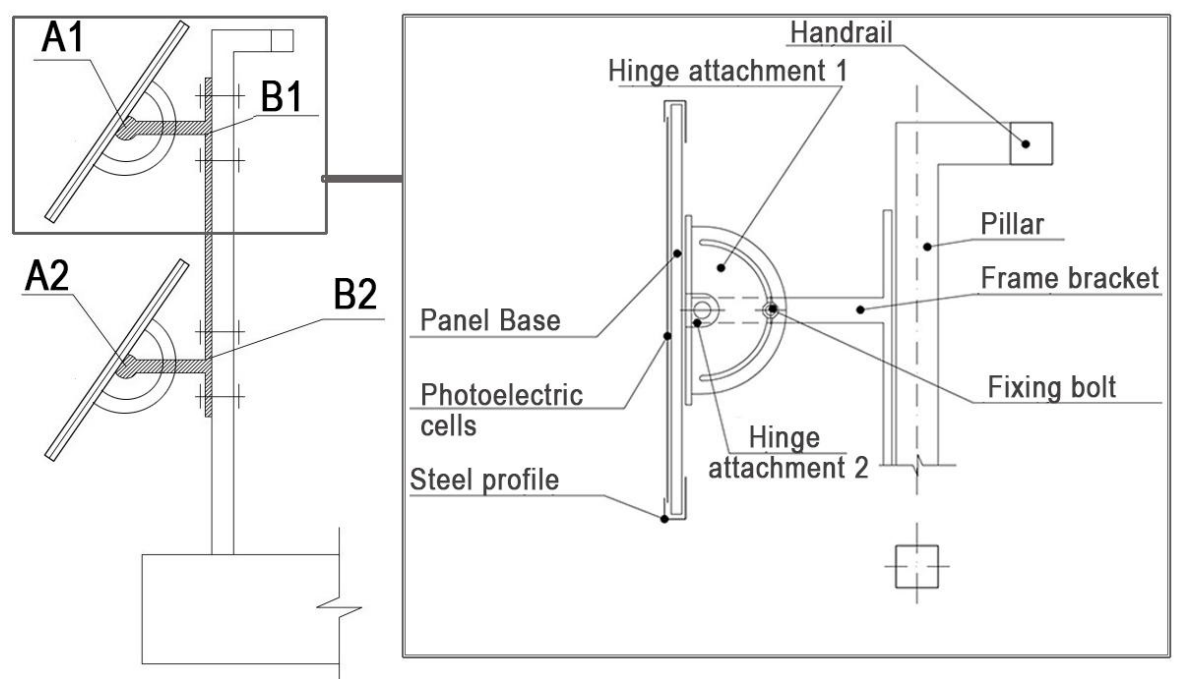

Fig. 4. Mounting photoelectric panels design module "PB".

Single-axis bracket module has a total base of the upper and lower mounting solar panels to provide rigidity. Horizontal guide statically mounted on a common base at the points B1 and B2. At the points A1 and A2 solar panel pivotally mounted on a horizontal rail. To solve the problem of shading upper bottom panel A2-B2 bracket should have a telescopic design or a predetermined extended length. 
To solve the problem of the module for orientation of photoelectric panels further rotation associated with not only their axis on a horizontal axis but also about a vertical axis for orientation module panels towards the sun for more efficiency, this design can be implemented by uniaxial bracket. During detailed design, dimensions can be changed.

\section{4 "Photoelectric barrier" in the scheme of power supply}

For the energy conversion process module into electrical light, which can be used for supply of domestic users, its needed power supply system, comprising a module "PB".

Autonomous power supply system with "PB" module consists of the following components:

1. Module "PB" with necessary power;

2. The battery charge controller, which prevents harmful to the battery deep discharge and overcharging;

3. Accumulator battery (than AB);

4. The inverter, which converts direct current into alternating (for $220 \mathrm{~V}$ );

5. Energy efficient continuous load and / or alternating current

Power supply system using the modules "PB" and the use of the electricity grid should be supplemented by automatic switching unit to the electricity grid.

Batteries determine the reliability and efficiency of the electrical system. You must use the rechargeable battery, which can be a long time to work in severe cyclic conditions. Charging $\mathrm{AB}$ is small currents. Tanks battery at an autonomous power supply system should be enough to ensure the load for a few days, so you need to choose the type and capacity of the battery corresponding to the task. These measures correspond to lead-acid batteries. Another kind of used batteries - lithium-ion batteries, but due to uneconomical almost do not apply to stand-alone power supply system's [12].

An important element of the solar system is a charge controller / battery discharge. The correct choice of controller can affect system performance and longevity of the AB [12]. There are different types of controllers - from the simplest, in which when a certain threshold voltage is shut down solar modules or load to the microprocessor, which made tracking the maximum power point of the solar modules and pulse width modulation (hereinafter PWM) charging current. PWM AB allow you to charge up to $100 \%$ (the simplest controllers typically charge $60-70 \% \mathrm{AB}$; systematic undercharging battery leads to rapid failure of its failure).

To ensure reliable power supply is needed the backup power supply. When independent power source such as a wind turbine or can be a small petrol or diesel electric generator $[13,14]$. When centralized power supply module with "PB" to reduce the costs of energy supply as a backup source can be a centralized power supply network. When battery power battery controller using automation unit can either transfer the load on centralized power network, or turn on the charger for a quick battery charge.

\section{Conclusion}

The reliability of the module structure "Photoelectric barrier" depends on its structural rigidity and mounting, quality, reliability and number of elements used. Prefabricated structural components type compound can occupy a small volume for storage and transportation of the fence, which reflects its universality. Welded components are large compared to the size of the teams of the elements due to the impossibility to ensure the welding process at the site of application design and provide the necessary strength properties of the compounds, and aesthetic properties [14]. 
Therefore the optimal design scheme should include the largest possible number of elements manufactured at the plant are connected by welds, and to ensure the mobility and versatility of the design elements have mounted directly onto the application site prefabricated construction method.

Application design modules "PB" is acceptable for both stand-alone systems, backup and auxiliary power supply to consumers and the design parameters obtained allow to install the module on the most southern of balconies and loggias, south-west, south-east orientation.

This work was financially supported by the Ministry of Education and Science of the Russian Federation within the framework of the state order to MGSU №2014/107 project "Fundamental studies of wind effects (including extreme) to the unique building and bridge structures".

\section{References}

1. D.S. Strebkov, Y.D. Arbuzov, V.M. Evdokimov, V.A. Mayrov, V.I. Polyakov, Photovoltaic modules concentrate the radiation on the basis of the matrix of silicon solar cells Low energy, Recurrent scientific and technical journal 1-2 (2011)

2. Y.Y. Rafikova, S.V. Kiseleva, L.V. Nefedova, The use of renewable energy GIS technologies: foreign and domestic experience, International Journal of Alternative Energy and Ecology 12 (152), 96-106 (2014)

3. O. Shepovalova, D. Strebkov, I. Dunichkin, Energetically Independent Buildings of the Resort-improving and Educational-recreational Complex in Ecological Settlement GENOM, Colorado Renewable Energy Society (CRES) Annual Conference, 37673772 (2012)

4. The Sanitary Regulations and Norms (SanR and N) 2.2.1/2.1.1.1076-01 Hygienic requirements for sun exposure and sun protection facilities of residential and public buildings and areas (2002)

5. SP 20.13330.2011 The updated edition of SNiP 2.01.07-85* Loads and effects, JSC "LAC" (2011)

6. O. Poddaeva, S. Trushin, P. Churin, A. Zubkov, Experimental study of extreme wind loads on tall buildings and facilities, International Journal of Applied Engineering Research 21, 42797-42799 (2015).

7. P.S. Churin, J.S. Buslaeva, Experimental Study Of Wind And Snow Influence On The Unique Buildings And Facilities, International Journal of Applied Engineering Research 20, 40841-40843 (2015)

8. A.A. Soloviev, S.D. Varfolomeyev, P.P. Bezrukikh, O.S. Popel, A.B. Tarasenko, E.V. Antipov, G.V. Tomarov, M.V. Slipenchuk, E.I. Golubeva, S.V. Kiseleva, V.G. Nikolaev, Y.I. Blyashko, G.V. Ermolenko, I.Y. Yegorov, N.I. Chernova, Renewable energy: Lectures. Release 8 (2015)

9. D.S. Strebkov., A.E. Irodionov, Global solar power system, Eurosun - 2004 2, 336343 (2004)

10. Renewable energy technologies and energy-saving equipment. Catalog of technologies and products, developed within GNU VIESH, GNU VIES (2009)

11. GOST 25772-83 Fences of stairways, balconies and roofs of steel (1983)

12. A.P. Kashkarov, Wind turbine, solar panels and other useful design (2011)

13. E. Duraeva, Renewable energy in Russia from possibility to reality, OECD / IEA (2004)

14. I.A. Polyakov, S.V. Ilvitskaya, Thesaurus architectural mentality of the XXI century, Russian Architecture and Building 1-2, 166-167 (2016) 